\title{
LITERATURA INFANTIL E EDUCAÇÃO: CONVERGÊNCIA OU CAMINHO UNÍSSONO?
}

\author{
Adriana Batista de Souza Koide* \\ Jussara Cristina Barboza Tortella ${ }^{* *}$
}

\begin{abstract}
Resumo: Assumindo uma postura pedagógica, por séculos, o livro infantil trouxe lições moralizantes que se constituíram em um meio eficaz para instaurar e mensurar condutas e modelos. Perante essa visão, a escola assumiu a interpretação errônea de que a literatura infantil deveria ser objeto de estudo antes de ser objeto de experiência pessoal e intransferível. Nesse contexto, sob a perspectiva teórica sócio-cognitiva, trazemos o recorte de uma pesquisa de mestrado em andamento, que pretende verificar convergências e unicidades entre literatura infantil e escola, respondendo a seguinte questão: Há espaço para as narrativas literárias na escola de educação infantil? Ao discutir esse assunto, pretendemos fomentar debates a respeito da educação pela literatura, que rivaliza com a educação para a literatura, superando dicotomias.
\end{abstract}

Palavras-chave: Literatura infantil. Educação Infantil. Formação humana. Fruição.

\begin{abstract}
From a pedagogical approach, for centuries, children's books brought moralizing lessons that consisted effective means to establish and measure behaviors and models. Given this view, the school took the misinterpretation that children's literature should be studied before being subject to personal and non-transferable experience. In this context, under the socio-cognitive theoretical perspective, we bring the cutting of an in progress master's research that intends to verify convergences and oneness between children's literature and school by answering the question: Is there room for literary narratives in children's education school? In discussing this issue, we want to encourage debates about education through literature, rivaling education for literature, overcoming dichotomies.
\end{abstract}

Keywords: Children's Literature. Children's education. Human formation. Fruition.

\section{Introdução}

Os livros infantis propiciam reflexões e descobertas e, enquanto arte, tratam sobre temas diversos. Cada época confere aos mesmos temas novas compreensões por meio de harmonia entre letras, imagens, poemas e atividades que permitem o contato com outras realidades, outras culturas e outros pontos de vista.

Utilizar histórias com o intuito de deixar marcas ou transmitir ensinamentos, criando memórias e reforçando tradições sempre foi uma necessidade do homem. Transitando entre a realidade e a fantasia, entrelaçando os mundos imaginário e real, a literatura infantil, desde seus primórdios, atravessa séculos encantando e despertando a imaginação, tal qual um espelho que reflete alegrias, desejos e medos. Contudo, a instituição educacional, por muito tempo, utilizou o livro infantil para transmitir normas e valores do mundo adulto, deixando de lado o deleite e a fruição. Essa postura fragmentada atribuiu aos textos literários destinados à criança uma postura exclusivamente educativa, minimizando-a enquanto arte. Diante disso, questionamos: nos dias contemporâneos, há espaço para as narrativas literárias na escola de educação infantil?

\footnotetext{
* Mestranda em Educação: PUC Campinas. Vice-diretora educacional da rede pública municipal de Campinas (SP). Integrante do grupo de pesquisa Formação e prática docente da linha de pesquisa Formação de professores e práticas pedagógicas da PUC Campinas. Endereço eletrônico: adrianabskoide@ gmail.com

** Doutora em Educação: Universidade Estadual de Campinas - Faculdade de Educação da Unicamp. Docente permanente do Programa de Pós-graduação em Educação da PUC Campinas. Integrante do grupo de pesquisa Formação e prática docente da linha de pesquisa Formação de professores e práticas pedagógicas da PUC Campinas. Endereço eletrônico: jussaratortella@gmail.com
} 
Buscando responder a essa questão, fizemos um levantamento de dados nas bases científicas CAPES, SCIELO e BDTD, utilizando as palavras-chave entrecruzadas. Os documentos selecionados, acrescidos por referências encontradas a partir dos primeiros textos, subsidiaram uma escrita que se divide em fundamentação teórica, tratando do livro para crianças, da formação humana e do texto literário na educação. Versando sobre experiências cotidianas, apresentamos um trabalho pedagógico no qual o uso da literatura infantil ocorre dentro de uma proposta humanizadora na Educação Infantil. Ao final, tecemos algumas considerações, intencionando demonstrar que as dicotomias pré-estabelecidas, entre literatura infantil e instituição educativa destinada para crianças pequenas, podem ser superadas com uma prática que enquanto forma, transforma.

$\mathrm{O}$ texto que trazemos aqui é parte integrante de uma pesquisa de mestrado em andamento, cujo foco consiste em utilizar a literatura infantil como meio de fruição, imaginação e formação humana de aprendizagens direcionadas que a criança adquire na infância e carrega consigo por toda a vida. $O$ estudo acontece em uma escola de Educação Infantil da rede pública do município de Campinas (SP), e envolve 45 educadoras e 354 crianças. A metodologia utilizada para a pesquisa do mestrado inclui: formação docente sob a temática da literatura infantil; observações em sala de aula; registros da pesquisadora e das educadoras envolvidas sobre as aulas e sobre a formação; registros sobre a troca de experiências entre as professoras; entrevistas com as docentes.

No desenvolvimento do presente relato, que se configura apenas como um recorte da pesquisa em andamento, foram utilizados os seguintes instrumentos: observações em sala e registros da professora e da pesquisadora.

Ao ampliarmos nossa voz para explicitar alguns projetos planejados e desenvolvidos a partir da literatura, em uma sala de aula da Educação Infantil, através das palavras aqui expressas, compartilharmos não apenas uma experiência assertiva. Pudemos com isso, também, reafirmar nossa postura diante de uma escola que necessita abrir espaço para que a literatura infantil faça parte da rotina educacional, tal qual nos propõem Costa, Ramos e Panozzo (2007, p. 138) quando dizem que a literatura infantil precisa pertencer à escola "sem o peso de um conteúdo programático, mas com a leveza do prazer e do encantamento que uma obra literária pode oferecer, com uma proposta de sentido que encontra ressonância na vida", ou, em outras palavras, carecemos de que a literatura esteja presente na escola de Educação Infantil trazendo consigo uma proposta humanizadora. É a essa questão que nossas atenções se dedicam.

\section{0 livro para crianças e a formação humana: do ontem ao hoje}

A literatura infantil, desde suas origens, está vinculada à educação. Os primeiros textos escritos para a criança foram elaborados por educadores e tinham como objetivo ensinar costumes e valores (VILHENA, 2014). Tratando desse assunto, Zilberman (2006), assevera que "escola e literatura são parceiras há muito tempo. Pode-se mesmo afirmar que a primeira nunca prescindiu da segunda".

Rodari (2004), informa que a literatura infantil surgiu a partir de uma necessidade pedagógica, didática. Dirigida à criança em idade escolar, a literatura trazia lições moralizantes que se constituíam em um meio eficaz para instaurar e mensurar condutas e modelos.

Concomitantemente com as primeiras impressões para as crianças, as primeiras escolas populares surgiram entre os séculos XVII e XVIII. A literatura foi necessária e fundamental nas escolas que educavam as crianças do povo. Virtudes e valores eram indispensáveis para as classes dominadas, em um tempo em que era preciso aprender e 
valorizar a obediência e o trabalho. A história da literatura infantil com a educação formal começa nesse contexto e ambas podiam ser compreendidas como veículos ideológicos dominadores (RODARI, 2004).

É válido lembrar também que as escolas surgiram quando a criança deixou de ser vista como um adulto em miniatura e passou a deter um papel novo e exclusivo na sociedade. Objetos comercializados especificamente para o público infantil, como brinquedos e livros, passaram a ser indispensáveis. Lajolo e Zilberman (2007, p. 16) ressaltam que "essa obrigatoriedade se justifica com uma lógica digna de nota: postulados a fragilidade e o despreparo dos pequenos, urgia equipará-los para o enfrentamento maduro do mundo".

Essa visão marcou o início da indústria livreira infantil e os objetivos dos primeiros escritores/educadores ainda podem ser notados na literatura infantil e na educação atuais. Ao dissertar sobre isso, Vilhena (2014, p.59) informa que "no fundo, o adulto despreza o saber da criança, fazendo um discurso que não condiz com a prática porque ele não se coloca disposto a aprender e ensinar a partir do saber da criança, mas, sim, busca oferecer uma aproximação ligeira do seu conhecimento para ela".

Embora literatura infantil e escola tenham origem em comum, Cosson (2014) expõe que a relação entre ambas está distante de ser pacífica. Nesse sentido, Mügge e Saraiva (2006, p. 28) acrescentam que o posicionamento contraditório da escola perante a literatura, acontece por erros conceituais que podem ser exemplificados pela interpretação errônea de que a literatura infantil "é objeto de estudo antes de ser objeto de uma experiência pessoal e intransferível”.

De acordo com Santos (2011), essa visão fragmentada fomentou e ainda fomenta o crescimento da literatura infantil. Para a autora, o que ampliou o comércio de livros infantis foi a preocupação com a formação da criança e não a atenção com o lazer, com o lúdico.

Zilberman (1982) afirma que o livro para crianças, desde sua origem, assumiu uma postura pedagógica. Com personalidade educativa, a literatura infantil englobava normas e valores do mundo adulto, preterindo o caráter lúdico. Para Santos (2011) a espécie literária e a escola tinham relações metafóricas simultâneas e complementares e por isso é importante salientar que o contexto educativo, com mais frequência do que deveria, "reitera perspectivas hegemônicas acerca dos modos de ser, de se comportar, de fazer, de possuir, de se relacionar com os outros, com as instituições, com o trabalho", e os livros selecionados pela escola denunciam abertamente o "modelo" de pessoas que ela pretende formar (SANTOS, 2011, p. 94).

Ao tratar sobre a finalidade da literatura infantil na contemporaneidade, Santos (2011) complementa nossa linha de pensamento com os seguintes dizeres:

Eis, portanto, a resposta que construí ao longo deste trabalho: literatura (infantil/juvenil ou não) para nos ajudar a sobreviver quando tudo parece perdido, quando nos falta a mãe, o pai, a habilidade de firmamentos. Poderia ser cinema, artes plásticas, música, quadrinhos, teatro, novela. No entanto, para mim, a literatura é o que chega mais perto, o que me comunica melhor, o que me afunda e me eleva, o que me aproxima de mim ou do que eu gostaria de ser; é o que me resgata do desamparo, desde a infância. (SANTOS, 2011, p. 204).

Do ontem ao hoje, a literatura tem um papel a cumprir dentro da escola, mas as severas críticas ao doutrinamento imposto por séculos pelo "texto pedagogizado" indicam que é fundamental uma reorganização entre literatura e educação, com papel centrado nos interesses da criança. 
Papel este, que permita que a leitura literária seja exercida com prazer, mas, também, com o compromisso de construção do conhecimento, já que na escola, a literatura é um lócus de conhecimento e deve ser desenvolvida de maneira correta com o objetivo de formar o sujeito intelectualmente e eticamente mais humanizado. (PAIVA; OLIVEIRA, 2010, p. 31-32).

As autoras supracitadas também dizem que a escola é o espaço para o encontro entre a criança e o livro. No entanto, a literatura infantil por si só constitui um espaço de conhecimento, assim como ocorre com a escola e ambas precisam ser exploradas de maneira adequada para que não retomem um caráter doutrinador. Dessa forma, é inevitável que a literatura infantil seja utilizada na/pela escola. Ambas nasceram juntas e são necessárias para o desenvolvimento infantil.

Todavia, o que necessita de reflexão é a forma como os textos literários infantis estão sendo utilizados na educação (COSTA; RAMOS; PANOZZO, 2007). A escolarização dessa modalidade literária precisa ser repensada, porque, do modo como acontece hoje, desvirtua a obra literária enquanto arte que ao ser deturpada e falseada, distancia-se do seu público.

Embora consideremos que ainda há dúvidas quanto à função e a utilização da literatura infantil na educação, visto que as relações entre ambas sempre foram motivo de discussões, podemos dizer que a literatura infantil pode e deve ser utilizada na escola, desde que não seja renegada enquanto arte.

\section{0 texto literário infantil como meio para formar e transformar}

Mortatti (2014) afirma que a literatura, em si e por si, educa e ensina. Em sua visão, a literatura infantil é o meio para a educação humana e não o instrumento. Por seu caráter mediador, as narrativas infantis constituem ações que modificam e transformam as crianças. Nesse sentido, a literatura infantil é, por si mesma, objeto de ensino, inacabado, dinâmico. É fruição e conhecimento, que acontecem através da relação entre a criança e o texto literário.

[...] os (bons) textos literários encantam e ensinam (obviamente, se lidos, ou pelo menos ouvidos), porque fazem diferença em nossas vidas, constituem experiências profundamente humanas [...], porque nos ajudam a formular perguntas para nossa vida, estimulam nossa sabedoria, nossa busca de conhecimento de nós mesmos e do mundo. Nesse sentido, encantam e ensinam, porque, lendo-os, aprendemos algo sobre nossa vida, ao mesmo tempo em que aprendemos sobre a importância da literatura na formação do ser humano [...] esses textos têm, portanto, uma função formativa específica. (MORTATTI, 2008, p. 27).

O que caracteriza um texto como literário não é o assunto ou o conteúdo. Não são as lições de comportamento ou os temas moralizantes que atuam como mediadores entre literatura e educação. O que aborda, como aborda, em que tempo e local, por quais motivos e para quem se fala constituem um conjunto de relações que formam e transformam (MORTATTI, 2014).

A experiência adquirida pelos textos literários permite saber e conhecer a vida por meio da experiência do outro. Ou seja, a ficção transformada em literatura é um processo formativo para a criança. "Ambas permitem que se diga o que não sabemos expressar, e nos falam de maneira mais precisa o que queremos dizer ao mundo e a nós mesmos" (COSSON, 2014, p.17). 
Por meio da materialidade das histórias literárias, pode se consagrar experiências imateriais, compartilhadas por uma ou muitas pessoas, a partir de conhecimentos similares ou divergentes sobre a arte literária em questão (SAMORI, 2012).

É possível observar a função humanizadora da literatura infantil como obra de arte quando as crianças reagem a ela e quando modificam sua visão de mundo, ou pelo que foi lido, ou mobilizado pelo comentário de um colega. $\mathrm{E}$ essa trama vai sendo tecida a partir de seus papéis sociais e modificada a cada nova leitura, a cada novo comentário. (SAMORI, 2012, p. 96).

Por tudo isso, podemos nutrir alguma esperança de que educação e literatura superem seus conflitos, atingindo resultados que se configurem em novos modos de pensar, sentir, querer e agir. Dentro desse contexto, apresentamos no próximo tópico, um relato de experiência que intenciona demonstrar que na prática cotidiana da Educação Infantil, isso não é impossível.

\section{A literatura infantil em uma proposta humanizadora}

A Educação Infantil é um cenário especial, para não dizer ideal, quando pensamos em possibilidades de encontro entre criança, livro infantil e aprendizagem humana, em uma convergência de vivências que se completam com mensagem das histórias, com a fala do outro, seja adulto ou criança, com o que se aprende vendo, ouvindo, recontando ou simplesmente brincando. Tratando sobre esse encontro, apresentamos um relato de experiência da turma do AGIIIB (ano de 2015), com crianças de três a seis anos, da escola municipal CEI Corujinha, situada no município de Campinas, interior do estado de São Paulo. Esse relato é um recorte de uma pesquisa de mestrado que objetivou analisar a literatura infantil como meio para a fruição e para a autorregulação da aprendizagem. Na referida pesquisa, caracterizada como um estudo de caso, utilizou-se como instrumentos para a produção do material empírico a entrevista semiestruturada, a observação das formações e da sala de aula que foram registradas no caderno de campo das pesquisadoras. É a partir desse último instrumento, que apresentamos um fragmento das tantas experiências observadas durante o estudo.

O dia letivo começava às $7 \mathrm{~h} 15 \mathrm{~m}$ em uma roda de conversa que, na maioria das vezes, mantinha-se fervorosa por perguntas, comentários, risos e muitas cantigas, escolhidas pelas crianças. Logo depois da roda de conversa, geralmente as crianças se sentavam confortavelmente em volta da professora da sala, porque na rotina da turma, esse era um momento especial, por ser a hora da história. Olhos arregalados, bocas abertas, sussurros escapulidos e gargalhadas contagiantes expressavam indignação, surpresa, alegria, dentre outros tantos sentimentos que somente a literatura infantil é capaz de proporcionar.

Para a professora C., a literatura infantil dentro da escola precisa ser trabalhada com dois propósitos, com os objetivos pedagógicos e com prazer. A professora relata que a criança se envolve com os livros e isso pode despertar, ou não, o prazer para ouvir ou contar uma história; pode despertar o gosto pelos livros e pela leitura, mesmo que ainda não saiba ler convencionalmente.

Em um dia logo no começo do ano de 2015, uma criança da turma se aproximou da professora e pediu um afago na cabeça. Depois de cada história contada, durante os dias que se seguiram, lá estava a criança procurando colo. Em uma ocasião a professora pegou o menino no colo e disse que ele estava parecendo um gatinho, querendo colo e carinho. As outras crianças da sala ouviram o comentário e começaram a brincar imitando gatinhos. 
Esse fato despertou o interesse da garotada, que passou a incluir na roda da conversa comentários a respeito de gatos e também a escolher livros sobre felinos. A escolha do nome da turma aconteceu nessa época e, por meio de votação, chegaram à "Gatinhos". Ao verem juntos diversos livros sobre felinos, as crianças se apaixonaram pela onça e depois de uma nova eleição, renomearam-se "Turma da onça". Fizeram mais algumas leituras e decidiram que "Turma do Leão" era ainda melhor e esse foi o nome definitivo para o AGIIIB, durante o ano todo.

Com o acirrado interesse das crianças sobre o assunto, uma das leituras propostas pela professora, de que as crianças gostaram muito, aconteceu a partir do livro "O mundo fascinante dos animais - Felinos" (BECKER, 2008). A última imagem do livro era a do gatomaracajá e ao vê-lo, L., de 5 anos, levantou a mão e perguntou: "Professora, como esse gato conseguiu usar as pintas da onça? ". A resposta imediata da professora C. foi: Vamos pesquisar? Nascia ali o Projeto Felinos. Outras atividades começaram a ser planejadas e outros livros selecionados para o projeto, juntamente com as crianças, durante as rodas de conversa.

O embasamento do projeto Felinos aconteceu por meio da literatura infantil, que foi trabalhada com leituras, exposição de imagens e ilustrações dos livros, com brincadeiras, sendo complementada por reportagens de jornais e pesquisas tematizadas, que as crianças faziam na escola ou levavam para fazer em casa, com suas famílias. Uma visita ao zoológico para ver os felinos de perto também foi idealizada pelas crianças e realizada durante o desenvolvimento do projeto.

Com os livros da literatura infantil, com as pesquisas e as visitas, as crianças descobriram que os felinos saltam e sobem em árvores e têm garras e dentes afiados para caçarem. A partir do que vivenciaram, demonstraram o que aprenderam de forma lúdica e divertida. Até escolheram um local para subirem em árvores e caçarem, porém, diferentemente dos felinos, que sobrevivem caçando outros animais, as crianças optaram por "caçar" pitangas vermelhas e doces, deleitando-se com a degustação. Descobriram nesse momento que as garras fazem muita falta na hora de se equilibrar sobre os galhos das árvores que rodeiam a escola. $\mathrm{E}$ isso nem mesmo aparecia nos livros lidos e nas pesquisas que foram feitas pela turma.

A resposta para a questão de L. ainda não havia sido encontrada e por isso, a turminha optou por continuar a busca nos livros para crianças. Não encontraram muita coisa. Continuaram pesquisando em jornais e no tablet da professora. Depois de algum tempo com leituras diárias e muitas discussões, L. disse tranquilamente na roda da conversa: "Prô, já sei como o gato conseguiu usar as pintas da onça: os dois são felinos! ". Respondida a questão, o interesse pelos felinos foi amornando e a professora percebeu que o projeto chegava ao fim.

Uma necessidade da sala direcionou o trabalho pedagógico para outros rumos, até que surgisse um novo interesse, para um novo projeto.

Intencionando trabalhar expressões faciais, ampliar o repertório para as brincadeiras de faz-de-conta e para ajudar algumas crianças que respondiam com choro frequente às alterações rotineiras na escola, a professora reforçou na roda da conversa a importância de falar com outras pessoas sobre como se sentem, sobre o que pensam, incentivando as crianças a verbalizarem seus motivos de chateação ou de alegria. No entanto, a professora percebeu que somente o diálogo na roda da conversa não estava atingindo resultados satisfatórios, por isso ela foi em busca de livros da literatura infantil que pudessem canalizar melhor a mensagem que queria passar a respeito dos sentimentos.

Para começo de conversa, a professora C. levou um cartaz que mostrava diversos tipos de emoções, com variadas expressões faciais. Brincando de fazer caretas, a professora escolheu diversas obras literárias que contavam histórias tristes, felizes, de medo, trazendo referências como: O menino cachorro (BIBIAN, 2006); Chapeuzinho amarelo (BUARQUE, 
2003); Menina bonita do laço de fita (MACHADO, 2011); Quando me sinto feliz (MORONEY, 2013); Vira-lata (KING, 2005); Raposa (WILD, 2005), dentre outras. Com o incentivo por meio da literatura infantil, as crianças começaram a se expressar mais e perceberam que se queriam brincar com algum amigo em especial, seria melhor ter um sorriso no rosto, pois como a própria Turma do Leão comentou na roda da conversa, ninguém que fica com a cara fechada em um canto, isolado, atrai amigos.

Com essa iniciativa, a professora conseguiu levar as crianças a refletirem sobre a necessidade de expor por meio de palavras e expressões faciais os motivos de alegria, irritação, medo e tristeza e a grande maioria da turma passou a resolver seus conflitos por meio do diálogo. Contudo, algumas crianças ainda batiam nos colegas ou tentavam quebrar objetos, como forma de expressão de sua raiva, mesmo diante do apelo da professora e dos colegas para o diálogo. Por esse motivo, a busca por obras literárias que continuassem a auxiliar nessa questão, foi intensificada. Sobre isso, C. nos concedeu o seguinte relato:

Até que um dia eu li a história "Bocejo"1. Imediatamente as crianças lembraram-se de nossas conversas, das atividades, das caretas e brincadeiras. Sem vergonha nenhuma todas abriram a boca, bocejando. Falamos do que fazemos quando estamos com sono, alguns relataram que sentem sono quando esperam no consultório médico, outros quando estão sentados na igreja, outros contaram como bocejavam e dormiam em festas e no ônibus ao viajarem. Até que chegamos na página que mudaria todo meu planejamento da semana. Tinha o Albert Einstein mostrando a língua!!! A primeira pergunta das crianças: "quem é ele?" A minha resposta foi: vamos pesquisar? Eu estava com o tablet na sala, e pesquisamos fotos dele, quem era ele. Descobrimos seu nome e que era um homem muito inteligente! E então começou uma grande discussão: afinal, pode ou não pode mostrar a língua?

Depois de um debate acalorado, as crianças concluíram de que não é proibido mostrar a língua, mas acordaram que não podem fazer isso a todo momento, pois tem hora de brincar e tem hora de ficar sério. $\mathrm{O}$ interesse das crianças pela imagem do físico Albert Einstein instigou um novo projeto. A professora pesquisou um pouco mais sobre Einstein e tentou buscar uma de suas teorias que pudesse ser trabalhada com a Turma do Leão. O assunto era complexo e a insegurança de que talvez as crianças não conseguissem compreender o trabalho do físico, assombrava o planejamento. Mas em outra roda de conversa descobriram, pesquisando no tablete da professora, que Einstein acreditava não haver nada mais rápido do que a luz. As crianças ficaram muito curiosas para descobrir se isso era realmente um fato.

Durante nossas observações, avistamos B. (4 anos) propor para a turminha que apertassem o interruptor de luz e correr para ver se alguém conseguiria atravessar a sala antes que a luz acendesse. Se alguém conseguisse atravessar, ganharia a corrida da luz. Mas foi a luz quem ganhou a corrida todas as vezes, não importava o quanto as crianças corressem. Vimos ainda que, pesquisando, as crianças descobriram que a luz também é mais rápida que os carros de corrida e do que os aviões. Investigando mais um pouco, os pequenos descobriram ainda que não havia nada mais rápido do que a luz.

Enquanto tentavam descobrir uma forma de provar que Einsten estava errado, as crianças fizeram outras brincadeiras de correr e de pular, tentando ultrapassar a velocidade da luz. Buscavam coisas rápidas como assoprar uma bolinha com um canudo. Tentaram andar na motoca bem rápido. Nenhuma experiência que faziam conseguia ganhar da luz. Fizeram

\footnotetext{
1 (BRENMAN E MORICONI, 2012).
} 
atividades artísticas sobre a luz do sol e das estrelas. Viram livros sobre o sistema solar e pesquisaram outras formas de produção de luz, como velas, fósforos, luz elétrica, etc.

Enquanto observávamos, percebíamos que as crianças falavam muito sobre o conhecimento adquirido durante o projeto, notando que as pessoas não conseguiriam ser mais velozes do que a luz, por que isso só acontecia na imaginação, no pensamento. Foi fácil para o grupo entender que haviam finalmente conseguido ganhar a corrida, em relação à velocidade da luz, não com o corpo que se movimenta, mas com o cérebro, que ninguém vê porque fica escondido dentro da cabeça.

E depois que a corrida estava ganha, o interesse da Turma do leão novamente ganhou outros contornos, deixando como saldo, além do conhecimento adquirido, que será levado pelas crianças vida afora, o hábito de conversar mais sobre os sentimentos, evitando reagir com choros ou gritos. As brincadeiras ficaram mais amigáveis e o clima entre as crianças da turma, mais cooperativo.

A Turma do leão gostava muito de participar do Projeto Horta, realizado anualmente na escola. Gostava de afofar a terra e plantar as sementes, que viam nascer e crescer. Gostava de ver os bichinhos que vivem na horta. $\mathrm{O}$ interesse por esse assunto levou a professora à escolha do livro "O minhoco apaixonado", (ROSCOE, 2013).

Para incitar inicialmente a fruição, a curiosidade e a imaginação das crianças, a professora escondeu o livro dentro de uma sacola de papel, no armário da sala. Depois da roda da conversa, ela contou para as crianças que o livro estava escondido e a turma toda se interessou para sair procurando. Brincando de quente e frio, as crianças encontraram o livro. Exploraram o livro por fora, descobriram quem era a autora e a ilustradora para depois fazerem a leitura com a professora e o reconto da história.

Uma das crianças explicou que quando está sem óculos, também não consegue enxergar direito, igual ao personagem da história. Em outra roda de conversa, as crianças afirmaram que queriam ver novamente as minhocas de verdade e sugeriram ir para a horta, cavoucar a terra, para encontrá-las.

Nas rodas de conversa subsequentes, quando a professora retomava com as crianças o que havia sido interessante, era comum uma grande parte responder que gostaria que ela (professora) escondesse o livro novamente, que contasse mais histórias de um jeito diferente. Ao que a professora C. nos respondeu posteriormente que antes tinha esse hábito, fazia leitura em lugares peculiares ou com o auxílio de objetos diferentes, mas com uma rotina diária fixa, tal hábito ficou adormecido durante o ano de 2015.

Buscando analisar o material coletado e citado acima, reforçamos alguns apontamentos já descritos ao longo do texto, salientando o entendimento de que a literatura infantil tem realmente o poder de nos fazer ver o que está oculto, sejamos adultos ou crianças. Constatamos que pela literatura infantil podemos nos imaginar mais fortes do que um leão, mais rápidos do que a luz ou mais delicados e sensíveis do que uma frágil minhoca da horta. Pela literatura infantil podemos nos tornar mais humanos2.

\section{Algumas considerações}

O relato que acabamos de socializar enfoca a importância de um trabalho pedagógico planejado e sistematizado a partir da literatura infantil, considerando no decorrer de todo o processo, seja no planejamento, no desenvolvimento, ou na avaliação, o interesse da criança, sua fala, suas expressões, seus sentimentos. Dessa forma, enfatizamos a necessidade de que a escola de Educação Infantil considere o ponto de vista da criança. A escolha das obras, a

\footnotetext{
${ }^{2}$ É oportuno lembrar que o presente artigo, visto como um relato de experiência, é excerto de uma pesquisa de mestrado em andamento e por isso não apresenta ainda os resultados de análise conclusivos.
} 
reflexão sobre o texto e a apreciação pessoal são formas de colocar a arte a serviço da formação da infância.

É necessário superar as marcas "pedagogizantes da literatura infantil, em decorrências de sua relação original com a educação e com a escola" (MORTATTI, 2014, p. 27). Esse é o ponto de convergência entre literatura para crianças e o contexto educacional, instâncias que se completam na formação humana, tal como a defendemos no decorrer de nossa escrita, enquanto buscamos entrelaçar teoria e prática.

Há espaço para as narrativas literárias na escola de educação infantil? Fundamentadas no que estudamos na teoria e aqui apresentamos, associando esses conteúdos às vivências que tivemos na Educação Infantil, respondemos: Certamente! Porque não é possível conceber a educação da criança pequena sem a literatura.

Assim como toda criança precisa do alimento para viver, crescer, e se reconhecer como ser humano, igualmente, essa mesma criança precisa da literatura para desenvolver seu intelecto, para ampliar e enriquecer seu vocabulário, para compreender contextos e visões diferentes, para encontrar respostas, reais ou não, para seus sentimentos, medos e anseios.

Para transformar-se em um leão, em luz de vela, luz do sol, luz das estrelas ou em uma pequena minhoca, a criança precisa da imaginação aguçada, realçada ou encontrada na/pela literatura infantil. Contudo, ressaltamos que é preciso que a educação busque equilíbrios que apontem avanços, envolvendo reflexões que problematizem atitudes triviais e/ou exclusivamente moralistas. Acreditamos que isso poderá ocorrer mediante formações docentes contextualizadas e direcionadas para ampliar o entendimento sobre o real poder de fruição e de ensino que um livro para crianças pode revelar.

Consideramos ainda que também é necessário repensar estratégias que impulsionem a literatura para seu devido lugar, dentro da escola, compreendida em caráter artístico e utilizada como meio e não como instrumento para o desenvolvimento infantil. Pois ao ser utilizada enquanto meio para ensinar e sem se perder enquanto arte, a literatura infantil alcança sentimentos e modifica comportamentos. Podemos observar isso no relato anterior, destacando as possíveis mudanças estruturais e cognitivas, possibilitadas pela literatura infantil selecionada e utilizada como fruição e como meio para o ensino, sem que para isso a professora precisasse apelar para lições moralizantes.

Ao discutir esse assunto, pretendemos fomentar debates a respeito da educação pela literatura, reconhecida enquanto arte, que rivaliza com a educação para a literatura, superando dicotomias.

\section{Referências}

BECKER, G. O mundo fascinante dos animais: felinos. São Paulo: Girassol, 2008.

BIBIAN, S. O menino cachorro. São Paulo: Manati, 2006.

BRENMAN, I.; MORICONI, R. Bocejo. São Paulo: Companhia das letrinhas, 2012.

BUARQUE, C. Chapeuzinho Amarelo. São Paulo: José Olympio, 2003.

COSSON, R. Letramento literário: teoria e prática. São Paulo: Contexto, 2014.

COSTA, M. M.; RAMOS F. B.; PANOZZO, N. S. P. Educação infantil: literatura como espaço de fruição. In: Signo. Santa Cruz do Sul, v. 32, n. 53, p. 128-140, dez. 2007. 
KING, S. M. Vira-lata. São Paulo: Brinque Book, 2005.

LAJOLO, M.; ZILBERMAN, R. Literatura infantil brasileira: história e histórias. 6. ed. São Paulo: Ática, 2007.

MACHADO, A. M. Menina bonita do laço de fita. São Paulo: Ática Editora, 2011.

MORTATTI, M. do R. L. Literatura e ensino: notas ¿quixotescas? Leitura. Teoria \& Prática, n. 50-51, p. 25-31, 2008.

O direito ao texto. In: BARCELOS, V.; ANTUNES, H. S. Alfabetização, Letramento e Leitura: territórios formativos. Santa Cruz do Sul-RS: EdUNISC, 2010, p. 137-148.

Na história do ensino da literatura no Brasil: problemas e possibilidades para o século XXI. Educar em revista, n. 52, p. 23-43, 2014.

MORONEY, T. Quando me sinto feliz. São Paulo: Ciranda Cultural, 2013.

PAIVA, S. C. F.; OLIVEIRA, A. A. A literatura infantil no processo de formação do leitor. In: Cadernos da Pedagogia. São Carlos, Ano 4, v. 4 n. 7, p. 22-36, jan -jun. 2010.

RODARI, G. La imaginación en la literatura infantil. Artigo publicado originalmente na revista Perspectiva Escolar, n. 43, da Associación de Mestres Rosa Sensat, Barcelona, Espanha e reproduzido pela revista Imaginaria, n. 125, 31 de mar. 2004.

ROSCOE, A. P. O minhoco apaixonado. São Paulo: Canguru, 2013.

SAMORI, D. P. Literatura infantil e experiências cotidianas: relações estabelecidas por crianças. In: Revista Educação por Escrito, PUCRS, v. 3, n.1, jul. 2012.

SANTOS, M. de M. Por um lugar para a literatura infantil/juvenil nos estudos literários. Tese (Doutorado em Letras e Linguística). Universidades Federal da Bahia: 2011.

VILHENA, R. de A. T. Literatura na educação infantil: práticas pedagógicas e a formação da criança pequena. Dissertação (Mestrado em Educação). Universidade Nove de Julho, São Paulo: 2014.

WILD, M. Raposa. São Paulo: Brinque Book, 2005.

ZILBERMAN, R. Prefácio. In: MÜGGE, E.; SARAIVA, J. A. Literatura na escola: propostas para o ensino fundamental. Porto Alegre: Artmed, 2006, p. 6.

ZILBERMAN, R. Literatura infantil: livro, leitura, leitor. In: ZILBERMAN, R. (Org.). A produção cultural para a criança. Porto Alegre: Mercado Aberto, 1982.

Recebido em: abril de 2016.

Aprovado em: agosto de 2016. 